\title{
Is there a role of breast pathologist in diagnostic challenges of discordances in ER, PR, and HER2 between primary breast cancer and brain metastasis?
}

\author{
Kadri Altundag ${ }^{1}$ (D)
}

Received: 22 December 2017 / Accepted: 25 January 2018 / Published online: 31 January 2018

(c) Springer Science+Business Media, LLC, part of Springer Nature 2018

To the Editor,

I wish to congratulate Jung and their colleagues [1] for their study. They investigated the expression profiles of estrogen receptor (ER), progesterone receptor (PR), and human epidermal growth factor receptor 2 (HER2) in breast cancer brain metastasis (BCBM) and the existence of discordance between primary breast cancer and brain metastasis. A total of 37 patients underwent craniotomies for metastatic brain tumors. Receptor conversion in BCBMs was observed in over $50 \%$ of Korean patients, and HER 2 conversion was observed in $23.8 \%$ of patients in this study. First of all, this study is retrospective analysis. As it is understood, tumors' pathology from primary breast cancer and brain metastasis were not re-studied by one specific breast pathologist. In clinical practice, this kind of analysis may be problematic if the the primary and metastatic tumors were reported by different pathologists, especially if they are not specifically experienced in breast pathology. For example, Price et al. [2] conducted a retrospective review of 100 randomly selected inter-institutional pathology consultations for breast cancer patients. The study cohort consisted of 93 cases that met the inclusion criteria. Of these 93 cases, 6 had no discordance, 7 had discordance with no clinical impact, and 80 had discordance with potential for clinical impact. Therefore, a breast pathologist should revisit all pathologies both from primary breast cancer and brain metastasis to decrease interobserver variation of the pathological findings in the current study.

\section{Compliance with ethical standards}

Conflict of interest The author indicated no potential conflicts of interest.

\section{References}

1. Jung J, Lee SH, Park M, Youn JH, Shin SH, Gwak HS, Yoo H (2017) Discordances in ER, PR, and HER2 between primary breast cancer and brain metastasis. J Neurooncol. https://doi. org/10.1007/s11060-017-2717-0

2. Price JA, Grunfeld E, Barnes PJ, Rheaume DE, Rayson D (2010) Inter-institutional pathology consultations for breast cancer: impact on clinical oncology therapy recommendations. Curr Oncol 17:25e32
Kadri Altundag

altundag66@yahoo.com

1 MKA Breast Cancer Clinic, Tepe Prime, Cankaya, 06800 Ankara, Turkey 